\title{
E-cadherin and caveolin-1 alterations in the heart of rats having undergone chlorpromazine-induced toxicity
}

\author{
QUAN-YONG HUANG ${ }^{1}$, XUE-FANG LI $^{2}$ and SHUI-PING LIU ${ }^{3}$ \\ ${ }^{1}$ Department of Pathology, School of Basic Medical Sciences, Dali University, Dali; \\ ${ }^{2}$ School of Basic Medical Sciences, Dali University, Dali,Yunnan 671000; ${ }^{3}$ Department of Forensic Pathology, \\ Zhongshan School of Medicine, Sun Yat-Sen University, Guangzhou 510080, P.R. China
}

Received October 10, 2011; Accepted December 15, 2011

DOI: $10.3892 / \mathrm{mmr} .2011 .729$

\begin{abstract}
Heart damage induced by chlorpromazine (CPZ) toxicity is associated with changes in the expression of various enzymes and proteins. This study aimed to investigate CPZ-induced alterations in cardiac E-cadherin and caveolin-1 (cav-1) after CPZ administration. Male Wistar rats were randomly divided into two groups: a control group and a CPZ group. The CPZ group was administered CPZ intraperitoneally at a single dose of $10 \mathrm{mg} / \mathrm{kg}$ for 21 days; the controls were given the same amount of saline via the same route. On Day 22, the rats were anesthetized, and a thoracotomy was performed in all animals. Immunohistochemical analysis was performed to evaluate protein expression of E-cadherin and cav-1. Sections were analyzed by digital image analysis. Results of the present study revealed that cardiac protein expression of E-cadherin and cav-1 was altered after CPZ-induced toxicity in the rat. The expression of E-cadherin was significantly reduced, while expression of cav-1 was significantly increased after CPZ treatment, as supported by integrated optical density analysis, compared with the control $(\mathrm{P}<0.05)$. The current findings indicate that such changes in the expression of E-cadherin and cav-1 may be reflected in abnormal cardiac function, and these proteins may be useful in revealing the mechanisms underlying CPZ-induced toxicity and may also provide additional insight for further research.
\end{abstract}

\section{Introduction}

The discovery of the antipsychotic properties of chlorpromazine (CPZ) in the 1950s was a fundamental event in the practice of psychiatry and for the genesis of the so-called 'psychopharmacological revolution' (1). CPZ is currently one of the three antipsychotic drugs on the WHO Essential Drug List (2). CPZ, a first-generation antipsychotic drug, is effec-

Correspondence to: Dr Quan-Yong Huang, Department of Pathology, School of Basic Medical Sciences, Dali University, Xiaguan Wanhua Road, Dali, Yunnan 671000, P.R. China E-mail: hqy0726@126.com

Key words: E-cadherin, caveolin-1, chlorpromazine-induced toxicity tive in the treatment of schizophrenia (3). CPZ is also a potent antipsychotic agent and is widely used for the amelioration of anxiety, depression and psychosis (4,5). It was demonstrated that $\mathrm{CPZ}$ is a dopamine-receptor antagonist antipsychotic agent (6). CPZ, which remains a benchmark treatment for individuals with schizophrenia, has been described as a prooxidant compound (7). Moreover, CPZ is a phenothiazine derivative used clinically to control psychotic disorders, and has been found to exhibit anticancer activity (8). Therapeutic success of atypical antipsychotics has focused attention on the role of receptor systems other than the dopaminergic system in the pathophysiology of neuroleptic-associated acute and chronic extrapyramidal side effects (9).

CPZ is a classical neuroleptic drug which produces both therapeutic effects as well as unwanted side effects in humans such as sedation, autonomic, endocrine and neurological effects. Blockade of dopamine D-2 receptors caused by CPZ induces these untoward side effects (10). It has been shown that accumulation of CPZ in animal bodies causes side effects in the circulatory and nervous systems and has adverse effects on blood cells (11). Moreover, CPZ often causes side effects including cutaneous photosensitization and ocular damage (11). It also has been demonstrated that CPZ treatment results in cardiovascular diseases. Many cases of sudden CPZ-related deaths have been identified in forensic autopsies (12).

CPZ-induced toxicity is associated with changes in superoxide dismutase and catalase activities (13). However, little is known concerning changes in E-cadherin and caveolin-1 (cav-1) expression in the heart after CPZ-induced toxicity.

The current study used immunohistochemistry to evaluate the expression of E-cadherin and cav-1 in the heart and to determine whether protein expression is altered upon CPZ-induced toxicity.

\section{Materials and methods}

Sixteen healthy adult male Wistar rats, weighing 180-210 g, were used in this study. All animals were maintained in a temperature- and humidity-controlled environment and a 12-h light and dark cycle. Rats were fed with a standard pellet chow and water throughout the experimental period. All procedures described in this study were approved by the Ethics Committee of Sun Yat-Sen University. 
Animals and study design. Animals were divided randomly into 2 groups, each with 8 rats. CPZ group animals were induced by an intraperitoneal injection of $\mathrm{CPZ}$ at a dose of $10 \mathrm{mg} / \mathrm{kg} /$ day for 21 days; the control group animals were only treated with normal saline for 21 days in equal volumes as for the experimental groups $(10,14)$.

After 21 days of treatment with CPZ (10 mg/kg/day), control and experimental animals were anesthetized with xylazine $(10 \mathrm{mg} / \mathrm{kg})$ and ketamine $\mathrm{HCl}(50 \mathrm{mg} / \mathrm{kg})$ and sacrificed. A thoracotomy was then performed. The heart was harvested, fixed in phosphate-buffered $10 \%$ formalin, embedded in paraffin wax, and sectioned $(4 \mu \mathrm{m})$ for light microscopy and immunohistochemical examination.

Histopathologic examinations. Heart specimens from each group were removed and examined histopathologically. The heart tissues were fixed in $10 \%$ formalin buffer, processed and embedded in paraffin, sectioned $(4 \mu \mathrm{m})$, and then stained with hematoxylin and eosin. The slides were coded and semiquantitative analysis of the sections was performed without knowledge of the treatment protocol. In these tissues, pathologic changes were evaluated $(15,16)$.

Tissue sections and immunohistochemical staining. All rat hearts were immersed in $4 \%$ formaldehyde solution with phosphate-buffered saline (PBS, $\mathrm{pH}$ 7.2), and embedded in paraffin, followed by sectioning coronally with a microtome into 4- $\mu \mathrm{m}$ sections. After deparaffinization, all sections were immersed in $0.3 \% \mathrm{H}_{2} \mathrm{O}_{2}$-PBS for $10 \mathrm{~min}$ and incubated with PBS containing $1 \%$ normal goat serum to reduce nonspecific reactions. After incubation with either rabbit antiE-cadherin, or anti-cav-1 (Santa Cruz Biotechnology, USA) overnight at $4{ }^{\circ} \mathrm{C}$, tissue sections were washed three times in phosphate-buffered saline (PBS) and incubated with biotinconjugated secondary antibody for $1 \mathrm{~h}$ at room temperature according to the manufacturer's instructions. The specimens were then incubated with peroxidase-conjugated avidinbiotin for $30 \mathrm{~min}$ at room temperature, and positive reactions were visualized with diaminobenzidine (DAB) (17-19). Two negative control sections were used, incubated only with the primary or the secondary antibody, respectively.

Total integrated optical density (IOD), a parameter representing expression levels of E-cadherin and cav-1 in cardiac tissue, was determined using a cast-grid microscope (MetaMorph/DP10/Bx41, UIC/Olympus, US/JP) together with an image-analysis program (MetaMorph offline, version 4.65). Under a magnification of $\mathrm{x} 400$, five images were captured in each immunostained section and the average calculated $(18,19)$.

Statistical analyses. Statistical analyses were performed by using SPSS 11.0 software. The results were presented as the mean \pm SEM. The sources of variation were analyzed by unpaired Student's t-test. A P-value of $<0.05$ was considered to be statistically significant.

\section{Results}

Histological examination. Routine histological examination revealed little morphologic change in rat hearts from each group (data not shown).
Immunohistochemical staining. Immunohistochemical staining was performed on formalin-fixed, paraffin-embedded sections from all parts of the heart including the conduction system.

Expression of E-cadherin protein. Positive staining for E-cadherin antibody was detected mainly in the extracellular matrix. The E-cadherin antibody was manifested as fine brown granularity. Two observers examined the sections independently.

Positive expression of E-cadherin in the control (Fig. 1A) and CPZ-injured rat hearts (Fig. 1B) was noted. Total IOD expression of E-cadherin in the rat hearts from each group is documented in Table I. Total IOD expression of E-cadherin in hearts from rats having undergone CPZ-induced toxicity was significantly lower than that found in the control $(\mathrm{P}<0.05)$.

Expression of caveolin-1 protein. The cav-1 staining was detected mainly in the extracellular matrix, and positive staining for cav-1 was manifested as fine brown granularity.

The distribution of cav-1 in the rat hearts of the control and CPZ groups is displayed in Fig. 2A and B, respectively. Total cav-1 IOD in the heart of animals subjected to CPZ-induced toxicity was significantly higher than that of the control hearts (Table I) $(\mathrm{P}<0.05)$.

\section{Discussion}

CPZ is widely used for the amelioration of anxiety, depression and psychosis. Yet, the undesirable associated side effects decrease the quality of life of patients to a great extent.

Cadherins are a large family of cell-cell adhesion molecules that tether cytoskeletal networks of actin and intermediate filaments to the plasma membrane (20). It is a superfamily of $\mathrm{Ca}(2+)$-dependent cell surface glycoproteins that play a morphogenetic role in a wide variety of developmental processes (21). Cadherins are essential components of adherens junction complexes that mediate cell-cell adhesion and regulate cell motility (22). It is also a major adhesion molecule regulating cell-cell and cell-matrix interactions (23). Cadherins are $\mathrm{Ca}(2+)$-dependent cell-cell adhesion proteins with an extracellular region of five domains (24), and are $\mathrm{Ca}(2+)$-dependent transmembrane proteins that are associated with actin via other cytoplasmic proteins (25).

E-cadherin is a member of the cadherin family of $\mathrm{Ca}(2+)$-dependent cell-cell adhesion molecules (26). It is a $120 \mathrm{kDa}$ cell-cell adhesion molecule involved in the establishment of epithelial adherens junctions (27), and also is an important cell adhesion molecule that plays paramount roles in organ development and the maintenance of tissue integrity and normal epithelial cell phenotype (28). E-cadherin, a cell adhesion protein, has been shown to take part in the compartmentalization, proliferation, survival and differentiation of cells (29). Maintenance of E-cadherin mediated cell-cell contacts is often required for the survival of epithelial cells and tissues (30). E-cadherin is a cell structural protein that has an important role in cell-cell adhesion and epithelial development (31). It mediates cell-cell adhesion, which is essential for the maintenance of the architecture and integrity of epithelial tissues, and is often lost during carcinoma progression (32). 

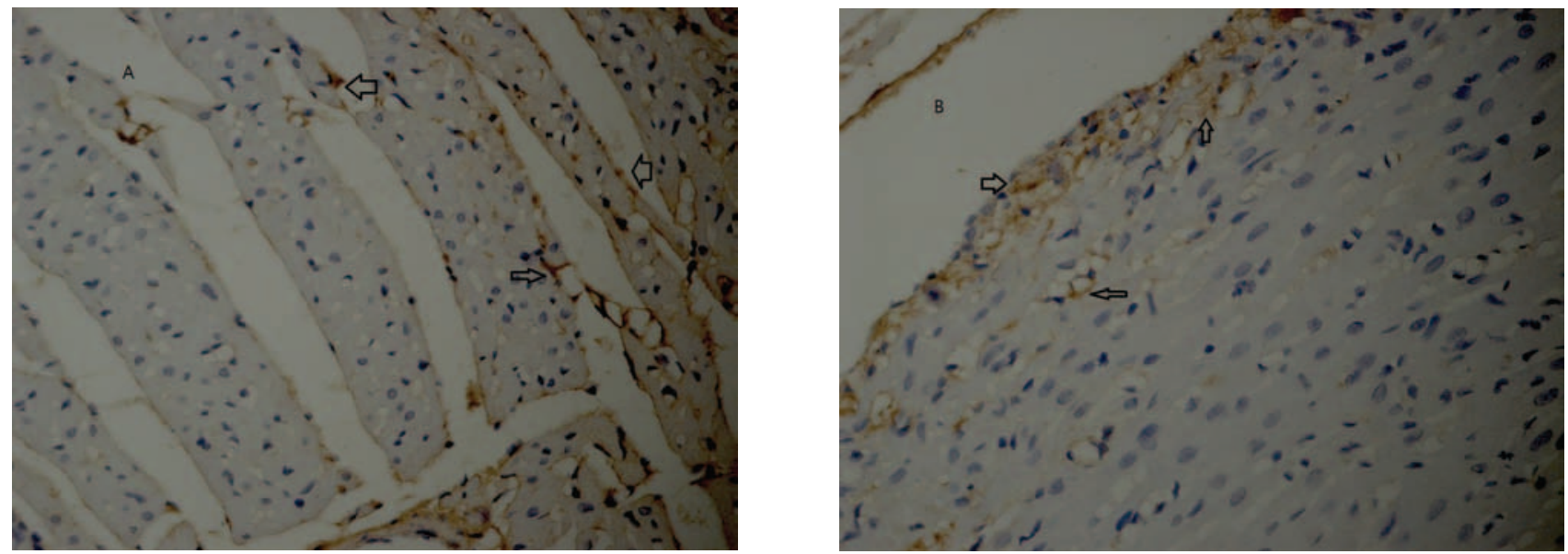

Figure 1. Effect of chlorpromazine-induced toxicity on E-cadherin expression in the rat heart. Photomicrographs display a representative distribution of E-cadherin positive expression in hearts from the (A) control and (B) chlorpromazine-exposed group. All photomicrographs were captured at a magnification of $\mathrm{x} 400$. Positive immunostaining appears as brown staining (arrow).
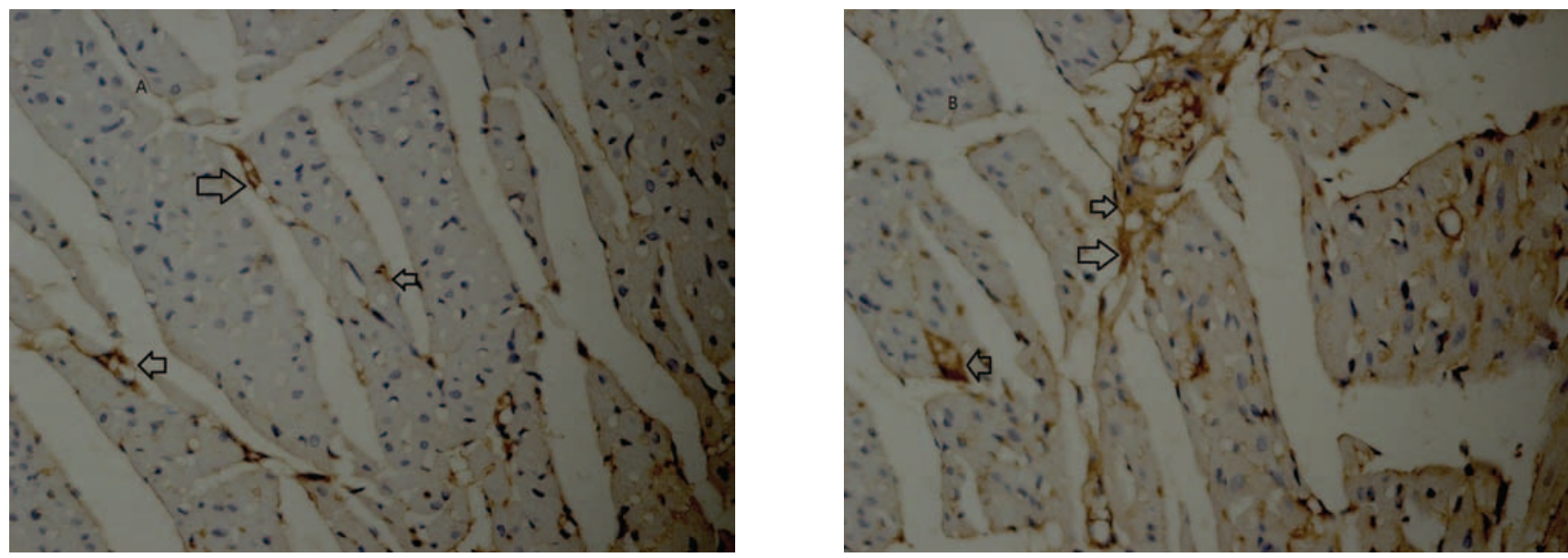

Figure 2. Effect of chlorpromazine-induced toxicity on caveolin-1 expression in rat hearts. Photomicrographs reveal a representative distribution of positive caveolin-1 expression in hearts from the (A) control and (B) chlorpromazine-exposed group. All photomicrographs were captured at a magnification of x400. Positive immunostaining appears as brown staining (arrow).

Table I. The integrated optical density (IOD) of E-cadherin and caveolin-1 in heart of rats.

\begin{tabular}{lcc}
\hline Groups & E-cadherin & Caveolin- 1 \\
\hline Control group & $0.0126 \pm 0.00023$ & $0.0059 \pm 0.00043$ \\
Chlorpromazine group & $0.0064 \pm 0.00025$ & $0.0137 \pm 0.00071$ \\
\hline
\end{tabular}

The integrated optical density (IOD) per field is proportional to the total amount of staining. Total E-cadherin IOD expression in rat heart having undergone chlorpromazine-induced toxicity was significantly lower compared with control hearts $(\mathrm{P}<0.05)$. Total caveolin-1 expression in rat heart subjected to chlorpromazine-induced toxicity was significantly higher compared with the control $(\mathrm{P}<0.05)$.

The dynamic control of E-cadherin is critical for establishing and maintaining cell-cell junctions in epithelial cells (33). Decreased E-cadherin in the heart noted in our results suggests that the tissues were greatly damaged after undergoing CPZ-induced toxicity. The present study indicates that CPZ-induced toxicity causes decreased E-cadherin expression related to impaired heart function.

Cav-1, a 21- to 24-kDa integral membrane protein, is a major structural coat protein of caveolae, specialized plasma membrane invaginations involved in multiple cellular functions (34), including molecular transport, cell adhesion and signal transduction (35). Cav-1 plays crucial roles in the regulation of various physiologic and pathophysiologic processes such as oncogenic transformation and tumorigenesis, and tumor invasion and metastasis (36). Cav-1 is involved in cholesterol homoeostasis, transcytosis, endocytosis and signal transduction and is thought to play an important role in lipidogenesis (37). It has been reported that cav-1 is involved in the pathogenesis of ischemic injuries (38). It has also been suggested that cav-1-deficiency is associated with substantial urogenital alterations (39). Furthermore, chronic disruption of cav-1 protein expression in the kidney induces hypertension (40). It has been suggested that cav-1 plays an important part in regu- 
lating pulmonary permeability (41), and may be related to the development and progress of pulmonary fibrosis (42).

Cav-1 is a multifunctional protein that is tyrosine-phosphorylated in response to injury and has been implicated in ROS-mediated injury (43). Cav-1 is involved in the regulation of tight junction proteins and is modulated by oxidative stress (44). Mechanistically, tumor cells induce autophagy in adjacent cancer-associated fibroblasts via the loss of cav-1, which is sufficient to promote oxidative stress in stromal fibroblasts (45). The upregulation of cav-1 and cell motility by hydroxylfree radicals suggests an important role of ROS as a positive regulator of tumor progression $(46,47)$. Furthermore, cav-1 can play a stimulatory role in NO signaling (48). The impacts of cav-1 on hepatocarcinogenesis may occur partly through its modulation of eNOS (49). Endothelial cav-1 is an anchoring protein in plasma membrane caveolae where it binds endothelial nitric oxide synthase and limits its activation (50).

It has been suggested that cav-1 is an important regulator of $\gamma$-secretase activity (51). Excess cav-1 has been reported to play a role in age-dependent hyporesponsiveness to growth factors in vitro (52), and cav-1 interacts with large conductance $\mathrm{Ca}(2+)$-activated potassium channels and likely exerts a negative regulatory effect on the channel activity (53). It has been shown that cav-1 participates in the rapid signaling elicited by the hormone (54). Cav-1, the scaffolding protein of caveolae, has also been shown to play an important role in host defense and inflammation (55). Increased cav-1 in the heart noted in our results suggests that the tissues were greatly damaged after having undergoing CPZ-induced toxicity. The present study indicates that CPZ-induced toxicity causes increased cav-1 expression which is related to impairment of the heart function.

Our present study demonstrated that cardiac protein expression of E-cadherin and cav-1 is altered after CPZ-induced toxicity in the rat. After undergoing CPZ-induced toxicity, protein expression of E-cadherin was significantly reduced while cav-1 was significantly elevated. The present study indicates that CPZ-induced toxicity causes different alterations in heart proteins that may be related to cardiac-function deterioration.

In conclusion, the current findings indicate that alterations in E-cadherin and cav-1 expression may be reflected in abnormal cardiac function. The proteins identified in this study may be useful in revealing the mechanisms underlying CPZ-induced toxicity and may also provide further insight for further research.

\section{Acknowledgements}

This study was supported by a grant from the Natural Science Foundation of Guangdong Province, China (no. 4203003) and Guangdong Medical College (no. XQ0426).

\section{References}

1. Lopez-Munoz F, Alamo C, Cuenca E, Shen WW, Clervoy P and Rubio G: History of the discovery and clinical introduction of chlorpromazine. Ann Clin Psychiatry 17: 113-135, 2005.
2. Liu X and De Haan S: Chlorpromazine dose for people with schizophrenia. Cochrane Database Syst Rev 2: CD007778, 2009.

3. Almerie MQ, Alkhateeb H, Essali A, Matar HE and Rezk E: Cessation of medication for people with schizophrenia already stable on chlorpromazine. Cochrane Database Syst Rev 1: CD006329, 2007.

4. Ahyayaucha H, Gallego M, Casis O and Bennouna M: Changes in erythrocyte morphology induced by imipramine and chlorpromazine. J Physiol Biochem 62: 199-205, 2006.

5. Misztal-Dethloff B, Stepien H and Komorowski J: Effect of diazepam and chlorpromazine on proliferative activity and vascular endothelial growth factor (VEGF) secretion from cultured endothelial HECa10 cells in vitro. Pharmacol Rep 57: 670-674, 2005.

6. Viskin S, Berger M, Ish-Shalom M, et al: Intravenous chlorpromazine for the emergency treatment of uncontrolled symptomatic hypertension in the pre-hospital setting: data from 500 consecutive cases. Isr Med Assoc J 7: 812-815, 2005.

7. Ximenes VF, Rodrigues AP, Cabello C, de Menezes ML and Fernandes JR: The co-catalytic effect of chlorpromazine on peroxidase-mediated oxidation of melatonin: enhanced production of N1-acetyl-N2-formyl-5-methoxykynuramine. J Pineal Res 44: 115-120, 2008.

8. Shin SY, Kim CG, Kim SH, Kim YS, Lim Y and Lee YH: Chlorpromazine activates p21Waf1/Cip1 gene transcription via early growth response-1 (Egr-1) in C6 glioma cells. Exp Mol Med 42: 395-405, 2010.

9. Kulkarni SK, Bishnoi M and Chopra K: In vivo microdialysis studies of striatal level of neurotransmitters after haloperidol and chlorpromazine administration. Indian J Exp Biol 47: 91-97, 2009.

10. Nsimba SE: Effects of daily chlorpromazine administration on behavioural and physiological parameters in the rat. Indian J Physiol Pharmacol 53: 209-218, 2009.

11. Liu W, Li W, Yin W, et al: Preparation of a monoclonal antibody and development of an indirect competitive ELISA for the detection of chlorpromazine residue in chicken and swine liver. J Sci Food Agric 90: 1789-1795, 2010.

12. Sakai S, Ikematsu K, Matsuo A, Tsai CT and Nakasono I: Expression of C-fos, Fos-B, Fosl-1, Fosl-2, Dusp-1 and C-jun in the mouse heart after single and repeated chlorpromazine administrations. Leg Med (Tokyo) 12: 284-288, 2010.

13. Li T, Zhou Q, Zhang N and Luo Y: Toxic effects of chlorpromazine on Carassius auratus and its oxidative stress. J Environ Sci Health B 43: 638-643, 2008.

14. Xu B, Xu ZF, Deng Y and Yang JH: Protective effects of chlorpromazine and verapamil against cadmium-induced kidney damage in vivo. Exp Toxicol Pathol 62: 27-34, 2010.

15. Helin HO, Lundin ME, Laakso M, Lundin J, Helin HJ and Isola J: Virtual microscopy in prostate histopathology: simultaneous viewing of biopsies stained sequentially with hematoxylin and eosin, and alpha-methylacyl-coenzyme A racemase/p63 immunohistochemistry. J Urol 175: 495-499, 2006.

16. De Rossi A, Rocha LB and Rossi MA: Application of fluorescence microscopy on hematoxylin and eosin-stained sections of healthy and diseased teeth and supporting structures. J Oral Pathol Med 36: 377-381, 2007.

17. Smith PS, Parkinson IH and Leong AS: Principles of ploidy analysis by static cytometry. Clin Mol Pathol 49: M104-M111, 1996.

18. Dong J, Yin H, Liu W, Wang P, Jiang Y and Chen J: Congenital iodine deficiency and hypothyroidism impair LTP and decrease $\mathrm{C}$-fos and C-jun expression in rat hippocampus. Neurotoxicology 26: 417-426, 2005.

19. van Kuijk AW, Gerlag DM, Vos K, et al: A prospective, randomised, placebo-controlled study to identify biomarkers associated with active treatment in psoriatic arthritis: effects of adalimumab treatment on synovial tissue. Ann Rheum Dis 68: 1303-1309, 2009.

20. Delva E and Kowalczyk AP: Regulation of cadherin trafficking. Traffic 10: 259-267, 2009.

21. Hertel N and Redies C: Absence of layer-specific cadherin expression profiles in the neocortex of the reeler mutant mouse. Cereb Cortex 21: 1105-1117, 2011.

22. Lewis-Tuffin LJ, Rodriguez F, Giannini C, et al: Misregulated E-cadherin expression associated with an aggressive brain tumor phenotype. PLoS One 5: e13665, 2010.

23. Martinez-Rico C, Pincet F, Thiery JP and Dufour S: Integrins stimulate E-cadherin-mediated intercellular adhesion by regulating Src-kinase activation and actomyosin contractility. J Cell Sci 123: 712-722, 2010. 
24. Sivasankar S, Zhang Y, Nelson WJ and Chu S: Characterizing the initial encounter complex in cadherin adhesion. Structure 17: 1075-1081, 2009.

25. Baranwal S and Alahari SK: Molecular mechanisms controlling E-cadherin expression in breast cancer. Biochem Biophys Res Commun 384: 6-11, 2009.

26. Yang I, Chang O, Lu Q and Kim K: Delta-catenin affects the localization and stability of p120-catenin by competitively interacting with E-cadherin. Mol Cells 29: 233-237, 2010.

27. Lapyckyj L, Castillo LF, Matos ML, Gabrielli NM, Luthy IA and Vazquez-Levin MH: Expression analysis of epithelial cadherin and related proteins in IBH- 6 and IBH-4 human breast cancer cell lines. J Cell Physiol 222: 596-605, 2010.

28. Pontes J Jr, Srougi M, Borra PM, Dall' Oglio MF, Ribeiro-Filho LA and Leite KR: E-cadherin and beta-catenin loss of expression related to bone metastasis in prostate cancer. Appl Immunohistochem Mol Morphol 18: 179-184, 2010

29. Karpowicz P, Willaime-Morawek S, Balenci L, DeVeale B, Inoue $\mathrm{T}$ and van der Kooy D: E-Cadherin regulates neural stem cell self-renewal. J Neurosci 29: 3885-3896, 2009.

30. Espada J, Galaz S, Sanz-Rodriguez F, et al: Oncogenic H-Ras and PI3K signaling can inhibit E-cadherin-dependent apoptosis and promote cell survival after photodynamic therapy in mouse keratinocytes. J Cell Physiol 219: 84-93, 2009.

31. Ben Nasr H, Hamrita B, Batbout M, et al: A single nucleotide polymorphism in the E-cadherin gene promoter $-160 \mathrm{C} / \mathrm{A}$ is associated with risk of nasopharyngeal cancer. Clin Chim Acta 411: 1253-1257, 2010.

32. Ayollo DV, Zhitnyak IY, Vasiliev JM and Gloushankova NA Rearrangements of the actin cytoskeleton and E-cadherin-based adherens junctions caused by neoplasic transformation change cell-cell interactions. PLoS One 4: e8027, 2009.

33. Canel M, Serrels A, Anderson KI, Frame MC and Brunton VG: Use of photoactivation and photobleaching to monitor the dynamic regulation of E-cadherin at the plasma membrane. Cell Adh Migr 4: 491-501, 2010.

34. Tsai TH, Chen SF, Huang TY, et al: Impaired Cd14 and Cd36 expression, bacterial clearance, and Toll-like receptor 4-Myd88 signaling in caveolin-1-deleted macrophages and mice. Shock 35: 92-99, 2011.

35. Corn PG and Thompson TC: Identification of a novel prostate cancer biomarker, caveolin-1: implications and potential clinical benefit. Cancer Manag Res 2: 111-122, 2010.

36. Zhu H, Yue J, Pan Z, et al: Involvement of Caveolin-1 in repair of DNA damage through both homologous recombination and non-homologous end joining. PLoS One 5: e12055, 2010.

37. Mastrodonato M, Calamita G, Rossi R, et al: Altered distribution of caveolin-1 in early liver steatosis. Eur J Clin Invest 41: 642-651, 2011

38. Jasmin JF, Rengo G, Lymperopoulos A, et al: Caveolin-1 deficiency exacerbates cardiac dysfunction and reduces survival in mice with myocardial infarction. Am J Physiol Heart Circ Physiol 300: H1274-H1281, 2011.

39. Sadegh MK, Ekman M, Rippe C, et al: Biomechanical properties and innervation of the female caveolin-1-deficient detrusor. $\mathrm{Br} \mathrm{J}$ Pharmacol 162: 1156-1170, 2011

40. Gildea JJ, Kemp BA, Howell NL, Van Sciver RE, Carey RM and Felder RA: Inhibition of renal caveolin-1 reduces natriuresis and produces hypertension in sodium-loaded rats. Am J Physiol Renal Physiol 300: F914-F920, 2011.
41. Gao C, Li R, Huan J and Li W: Caveolin-1 siRNA increases the pulmonary microvascular and alveolar epithelial permeability in rats. J Trauma 70: 210-219, 2011

42. Ding H, Zhou FQ, Cai HR, Zhou YH and Meng FQ: [Expression of caveolin-1 and extracellular matrix induced by transforming growth factor betal in human fetal lung fibroblasts]. Zhonghua Jie He He Hu Xi Za Zhi 33: 280-283, 2010.

43. Borza CM, Chen X, Mathew S, et al: Integrin \{alpha\}1\{beta\} promotes caveolin-1 dephosphorylation by activating $\mathrm{T}$ cell protein-tyrosine phosphatase. J Biol Chem 285: 40114-40124, 2010.

44. Beauchesne E, Desjardins P, Butterworth RF and Hazell AS: Up-regulation of caveolin-1 and blood-brain barrier breakdown are attenuated by $\mathrm{N}$-acetylcysteine in thiamine deficiency. Neurochem Int 57: 830-837, 2010.

45. Trimmer C, Sotgia F, Whitaker-Menezes D, et al: Caveolin-1 and mitochondrial SOD2 (MnSOD) function as tumor suppressors in the stromal microenvironment: a new genetically tractable model for human cancer associated fibroblasts. Cancer Biol Ther 11: 383-394, 2011.

46. Rungtabnapa P, Nimmannit U, Halim H, Rojanasakul Y and Chanvorachote P: Hydrogen peroxide inhibits non-small cell lung cancer cell anoikis through the inhibition of caveolin-1 degradation. Am J Physiol Cell Physiol 300: C235-C245, 2011.

47. Luanpitpong S, Talbott SJ, Rojanasakul Y, et al: Regulation of lung cancer cell migration and invasion by reactive oxygen species and caveolin-1. J Biol Chem 285: 38832-38840, 2010.

48. Tian J, Hou Y, Lu Q, et al: A novel role for caveolin-1 in regulating endothelial nitric oxide synthase activation in response to $\mathrm{H}_{2} \mathrm{O}_{2}$ and shear stress. Free Radic Biol Med 49: 159-170, 2010.

49. Yang SF, Yang JY, Huang CH, et al: Increased caveolin-1 expression associated with prolonged overall survival rate in hepatocellular carcinoma. Pathology 42: 438-445, 2010.

50. Pojoga LH, Adamova Z, Kumar A, et al: Sensitivity of NOS-dependent vascular relaxation pathway to mineralocorticoid receptor blockade in caveolin-1-deficient mice. Am J Physiol Heart Circ Physiol 298: H1776-H1788, 2010.

51. Kapoor A, Hsu WM, Wang BJ, et al: Caveolin-1 regulates $\gamma$-secretase-mediated A $\beta$ PP processing by modulating spatial distribution of $\gamma$-secretase in membrane. J Alzheimers Dis 22: 423-442, 2010.

52. Rhim JH, Kim JH, Yeo EJ, Kim JC and Park SC: Caveolin-1 as a novel indicator of wound-healing capacity in aged human corneal epithelium. Mol Med 16: 527-534, 2010.

53. Feher A, Rutkai I, Beleznai T, et al: Caveolin-1 limits the contribution of $\mathrm{BK}(\mathrm{Ca})$ channel to EDHF-mediated arteriolar dilation: implications in diet-induced obesity. Cardiovasc Res 87: 732-739, 2010.

54. Buitrago C and Boland R: Caveolae and caveolin-1 are implicated in 1alpha, 25(OH)2-vitamin D3-dependent modulation of Src, MAPK cascades and VDR localization in skeletal muscle cells. J Steroid Biochem Mol Biol 121: 169-175, 2010.

55. Mirza MK, Yuan J, Gao XP, et al: Caveolin-1 deficiency dampens Toll-like receptor 4 signaling through eNOS activation. Am J Pathol 176: 2344-2351, 2010 